\title{
ANALYSIS OF MPLS VPN RESISTANCE TO EXTERNAL THREATS
}

\section{ANALIZA ODPORNOŚCI MPLS VPN NA NARAŻENIA ZEWNĘTRZNE}

\author{
Marcin Pólkowski $^{1)}$, Dariusz Laskowski ${ }^{2)}$ \\ ${ }^{1)}$ Transbit Sp. z o.o., ${ }^{2)}$ Wojskowa Akademia Techniczna \\ e-mail:polkowski.marcin@gmail.com,dlaskowski@wat.edu.pl
}

\begin{abstract}
This article presents analysis and possible reactions of MPLS network on unauthorized access and on device's failure. Five Cisco routers joined into a core network were used to conduct the project. The devices were connected into a classic reliability model with envelope shape. The key aspects of the research were incidents' simulation in line with previously prepared scenarios as well as diagnosis of network's reactions to a particular type of a device failure. These effects were modelled using special devices such as analysers and generators of data traffic. Additionally, the range of the project included measuring convergence time of the routing protocols acting inside the network combined with analysis of reactions to forced changes of route.
\end{abstract}

Keywords: MPLS, security, reliability

Streszczenie: Artykuł zawiera analizę $i$ sprawdzenie możliwych reakcji sieci MPLS na ingerencję osób niepowołanych oraz na awarie urządzeń. Do jego realizacji wykorzystano routery firmy Cisco, na których została zbudowana badana sieć szkieletowa, która sktadała się z pięciu urządzeń. Zostały one połaczone $w$ klasyczny model niezawodnościowy $w$ kształcie koperty. Badania polegaty na symulowaniu zdarzeń wedtug wcześniej przygotowanych scenariuszy oraz diagnostyce zachowań sieci na poszczególne awarie. W tym celu uzyto analizatory i generatory ruchu sieciowego. Dodatkowo badano czasy zbieżności protokołów routingu działajacych wewnątrz sieci oraz sposobów ich reakcji na wymuszenia zmiany tras.

Slowa kluczowe: MPLS, bezpieczeństwo, niezawodność 
Analysis of MPLS VPN resistance to external threats

Analiza odporności MPLS VPN na narażenia zewnętrzne

\section{Wstęp}

Sieci telekomunikacyjne i sieci teleinformatyczne znajdują powszechne zastosowanie w różnego typu organizacjach ze względu na liczny zbiór własności technicznych wspierających niezawodność, bezpieczeństwo i jakość oferowanej palety usług. Jedną z ważniejszych usług jest wiarygodny i terminowy przesył danych między uprawnionymi terminalami sieciowymi spełniane przez odporne na narażenia techniki i technologie stosowane $\mathrm{w}$ strukturach szkieletowych. Reprezentatywnym i przyszłościowym mechanizmem jest Multiprotocol Label Switching (MPLS). Technika MPLS może zostać rozbudowana o wirtualne sieci prywatne (VPN) oferuje szeroką paletę usług umożliwiającą dostawcom usług projektowanie i wykonywanie nowoczesnych sieci szkieletowych, w których poszczególne usługi mogą zostać bezpiecznie odseparowane (MPLS VPN) adekwatnie do przyjętych determinant [1-3]. Osiąga się to poprzez zastosowanie zaawansowanych mechanizmów wspierających ciągłość dostarczania usługi dla klientów tj.:

- tablice informacyjne: VRF (Virtual Routing-Forwarding),

- protokoły wspierające poufność: IPsec (Internet Protocol Security) i SSL (ang. Secure Socket Layer),

- protokół routingu MP-BGP (Multiprotocol-Border Gateway Protocol) pozwoliło na budowę bezpiecznych sieci

- protokoły redundancji ścieżek: VRRP (Virtual Router Redundancy Protocol) i HSRP (Hot Standby Router Protocol).

Uwzględniając złożoność zalet i przyszłościowość techniki MPLS VPN wirtualizacja postanowiono poddać walidacji zalety wynikające $\mathrm{z}$ integracji własności ww. mechanizmów i protokołów. Proces sprawdzenia uwzględnił wieloaspektową analizę klasycznych i perspektywicznych zdolności dla reakcji w zakresie osiągnięcia i dotrzymania niejawności przesyłu danych (także danych wrażliwych) przed:

- ingerencją osób nieupoważnionych, czyli nieposiadających uprawnień do danej klasy lub zbioru usług,

- wpływem anomalii, czyli zamierzonych i niezamierzonych niezdatności będących wynikiem szkodliwego oddziaływania narażeń środowiskowych.

Biorąc za podstawę walidacji techniki MPLS wiarygodność i powtarzalności danych wynikowych postanowiono przeprowadzić badania $w$ warunkach symulacyjnych i badaniach miejscowych. W badaniach została wykorzystana platforma sprzętowo-programowa zawierająca urządzenia renomowanych producentów sprzętu telekomunikacyjnego i teleinformatycznego.

Srodowisko badawcze (testbed) odzwierciedlał powszechnie stosowaną $\mathrm{w}$ komercyjnych zastosowaniach architekturę sieci $\mathrm{z}$ wirtualizacją zasobów transportowych w obszarze szkieletu sieci. Metodyka badawcza zawierała elementy teorii diagnostyki i niezawodności. Determinanty bazowe ustalono na podstawie szczegółowej analizy reprezentatywnych uwarunkowań w zakresie rzeczywistych relacji sieciowych $\mathrm{z}$ wykorzystaniem generatorów usług $\mathrm{w}$ zdefiniowanych scenariuszach testowych. Monitoring zdarzeń był ciągły w czasie a anomalie rejestrowano w dzienniki zdarzeń budując składnicę wiedzy o zaistniałych epizodach. 


\section{Implementacja środowiska testowego}

Opracowana metodyka badań składała się z dwóch części: analitycznej (sprawdzającej poprawności i wariantowość konfiguracji w aplikacjach symulacyjnych) $i$ walidacyjnej w badaniach miejscowych na fizycznie istniejących urządzeniach platformy sprzętowo-programowej testbed-u.[4,5]

Usługa MPLS VPN została zaimplementowana na badanej sieci składającej się z pięciu routerów tworzących sieć szkieletową oraz czterech routerów klienckich (Rys. 1).

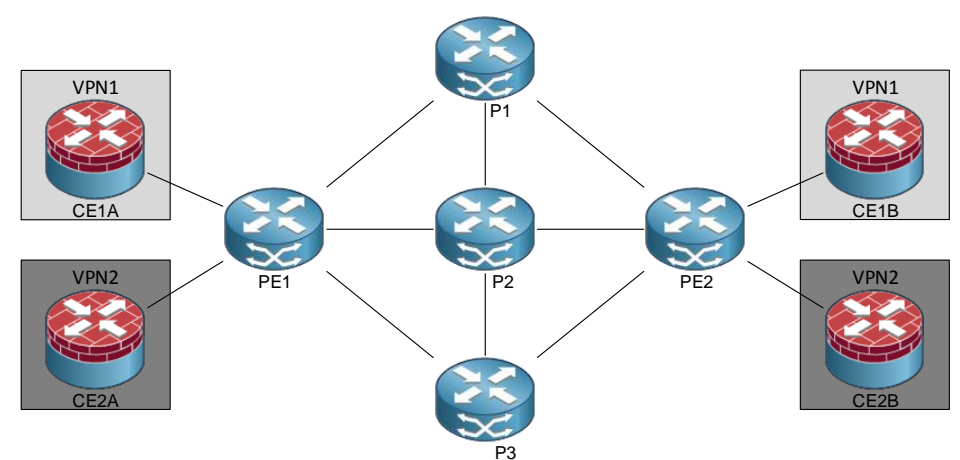

Rys. 1 Schemat stanowiska testowego

Pożądane własności test bed-u osiągnięto poprzez zapewnienie:

- efektywnego trasowania danych konfigurując metryki protokołu routing OSPF (Open Shortest Path First) z funkcją przełączania etykiet MPLS na routerach PX (P1, P2, P3, Provider) i PEY (PE1, PE2, Provider Edge);

- wymaganej poufności $w$ szyfrowanych tunelach IPsec utworzonych między routerami CE1A-CE1B i CE2A-CE2B (CE, Customer Edge).

Identyfikacja środowiska testowego została szczegółowo przedstawiona w publikacjach. [6-8] Taka konfiguracja pozwoliła na odseparowanie ruchu pakietów między routerami CE dołączonymi do jednego routera PE oraz dodatkowe szyfrowanie danych przesyłanych przez sieć szkieletową. Routery PE były w rzeczywistości wirtualnymi routerami zbudowanymi $\mathrm{z}$ dwóch routerów skonfigurowanych przy pomocy protokołów VRRP (Virtual Router Redundancy Protocol) lub HSRP (Hot Standby Router Protocol) - osiągnięto dodatkowo wariantowość implementacyjną poszerzającą paletę testów. Efektywne mechanizmy VRRP ${ }^{1}$ i $\mathrm{HSRP}^{2}$ są protokołami redundancji zasobów transportowych i wspierają niezawodnościowe własności sieci teleinformatycznych (Rys. 2). Pozwalają one na współdzielenie przez kilka routerów jednego adresu wspólnego IP wersji 4 lub 6 identyfikowanego, jako brama domyślna (DG) sieci wirtualnej. Wówczas to jeden z routerów zostaje tym głównym (Master), a pozostałe pełnią rolę zapasowych (Standby).

\footnotetext{
${ }^{1}$ Zgodny ze specyfikacją standardu RFC 3768 grupy rekomendującej IETF.

${ }^{2}$ Zgodny ze specyfikacją standardu RFC 2281 grupy rekomendującej IETF.
} 
Analysis of MPLS VPN resistance to external threats Analiza odporności MPLS VPN na narażenia zewnętrzne

Zastosowanie jednego $\mathrm{z}$ tych protokołów pozwala na zapewnienie ciągłości dostarczania usługi w razie awarii jednego z urządzeń.

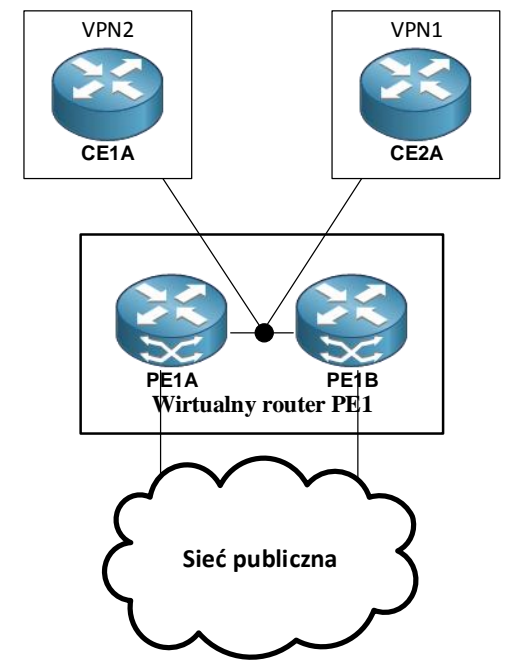

Rys. 2 Schemat pogladowy działania protokotów HSRP i VRRP

Oba protokoły HSRP i VRRP opierają się na podobnej zasadzie działania, ale różnią się w szczegółach, wybrane właściwości przedstawiono w tabeli (Tabela 1).

Tabela 1. Różnice w protokołach HSRP i VRRP

\begin{tabular}{|l|l|}
\hline \multicolumn{1}{|c|}{ HSRP } & \multicolumn{1}{c|}{ VRRP } \\
\hline Opatentowany & Bazuje na standardach \\
\hline RFC 2281 & RFC 3768 \\
\hline $\begin{array}{l}\text { Wykorzystuje jeden niewykorzystany } \\
\text { adres IPv4/6 z puli przydzielonych } \\
\text { adresów, jako adres wirtualny }\end{array}$ & $\begin{array}{l}\text { Może wykorzystać fizyczny adres } \\
\text { IPv4/6 routera głównego } \\
\text { (,oszczędność" puli adresowej) }\end{array}$ \\
\hline Master - 1 router, Standby - 1 router & $\begin{array}{l}\text { Master - 1 router, Standby - pozostałe } \\
\text { routery }\end{array}$ \\
\hline $\begin{array}{l}\text { Może zidentyfikować niezdatny } \\
\text { interfejs routera }\end{array}$ & $\begin{array}{l}\text { Może zidentyfikować niezdatny } \\
\text { interfejs routera oraz sprawdzić } \\
\text { osiągalność danego adresu IP4/6 }\end{array}$ \\
\hline $\begin{array}{l}\text { Wszystkie routery używają } \\
\text { multikastowej wiadomości hello }\end{array}$ & $\begin{array}{l}\text { Wszystkie routery używają } \\
\text { multikastowej wiadomości hello o } \\
\text { numerze protokołu 112 }\end{array}$ \\
\hline $\begin{array}{l}\text { Wszystkie routery muszą używać } \\
\text { adresów MAC w postaci } \\
\text { 0000.0c07.acXX, gdzie XX jest } \\
\text { oznacza ID grupy }\end{array}$ & $\begin{array}{l}\text { Wszystkie routery muszą używać } \\
\text { adresów MAC w postaci 00-00-5E- } \\
\text { 00-01-XX }\end{array}$ \\
\hline
\end{tabular}


Proces konfiguracji techniki MPLS VPN zawierał zasadnicze etapy tj.:

- dobór urządzeń i połączeń przewodowych, konfiguracja interfejsów GigabitEthernet i protokołów VRRP lub HSSR (zależnie od scenariusza) oraz OSPF,

- konfiguracja techniki MPLS i protokołu dystrybucji etykiet LDP (Label Distribution Protocol) z uwierzytelnianiem przy pomocy algorytmu MD5 (Message Digest 5),

- utworzenie tablic VRF na routerach PE, ustanowienie sesji MP-BGP między routerami PE i zestawienie tuneli IPsec między routerami CE,

- uruchomienie generatorów ruchu, analizatorów zdarzeń i monitorów niezdatności.

Z punktu widzenia bezpieczeństwa (poufności) i niezawodności (nieuszkadzalności) [9-12] krytycznymi aspektami konfiguracji była dokładna implementacja wszystkich szczegółowych uwarunkowań charakterystycznych dla techniki MPLS VPN i tuneli IPsec oraz zapasowych routerów.

\section{Schemat badań i wyniki}

Wieloaspektowość badań ukierunkowano na walidację funkcjonalności wybranych cech MPLS VPN poprzez liczność i różnorodność testów w ramach zdefiniowanych scenariuszy. Grupy scenariuszy miały na celu sprawdzenie poufności i nieuszkadalności sieci szkieletowej wykorzystującej etykietowanie pakietów MPLS w wariantach relacji sieciowych dla:

- uprawnionego routera posiadającego dopuszczenie do każdej klasy danych;

- nieautoryzowanego routera „udającego” jeden z routerów szkieletowych.

Badanie odporności sieci szkieletowej na nieautoryzowane podłączenie polegało na umieszczenie między dwoma uprawnionymi routerami jednego nieautoryzowanego routera (nieznającego id i hasta do uwierzytelniania sąsiednich routerów w protokołu LDP). Po tej czynności oryginalny router zgłaszał błąd autoryzacji (przykładowy wynik zaprezentowano na Rys. 3.).

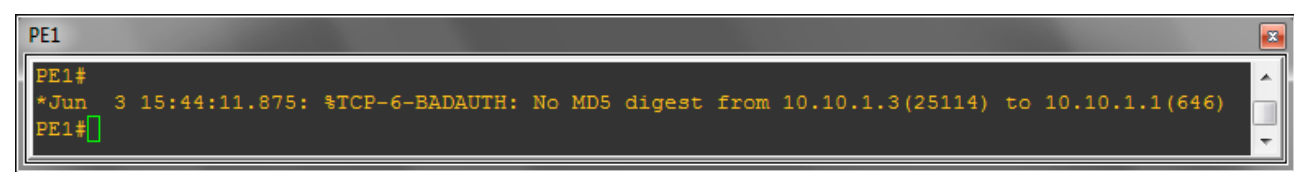

Rys. 3 Btad autoryzacji protokotu LDP.

W badaniach poszukiwano wiarygodnych danych będących podstawą budowania informacji o cechach MPLS VPN tj.:

- wartości czasu reakcji zapasowych routerów skonfigurowanych przy pomocy protokołów HSRP i VRRP w przypadku generowaniu ruchu pakietów o różnych wartościach przepływności;

- zależności przepływności różnych wielkości danych przesyłanych w zależności od stanu poszczególnych zasobów transportowych. 
Analysis of MPLS VPN resistance to external threats

Analiza odporności MPLS VPN na narażenia zewnętrzne

Przykładowo - badania czasu reakcji routerów na awarię routera głównego podzielono na cztery scenariusze: dwa dla protokołu HSRP $\mathrm{z}$ wartościami przepływnościami $(10 \mathrm{Mb} / \mathrm{s}$ i $100 \mathrm{Mb} / \mathrm{s})$ i analogiczne dwa dla protokołu VRRP. Pomiar czasu reakcji odbył się przy pomocy analizatora ruchu sieciowego Wireshark. Liczono go od momentu przerwania połączenia do rekonfiguracji sieci i uzyskania ponownego przepływu danych. Dla każdego scenariusza wykonano 30 powtórzeń w celu uśrednienia wyników. Do obliczenia wartości średniej wykorzystano medianę, $\mathrm{z}$ powodu jej odporności na zaburzenia związane ze znacznie odstającymi wynikami badania. W wyniku pomiarów uzyskano następujące wartości średnie (Tabela 2.)

Tabela 2. Uzyskane czasy reakcji routerów zastępczych

\begin{tabular}{|c|c|c|c|}
\hline \multirow{2}{*}{ Lp. } & $\begin{array}{c}\text { Wartość } \\
\text { przepływności }\end{array}$ & HSRP & VRRP \\
\cline { 2 - 4 }$\left[\begin{array}{c}|c| \\
{[\mathrm{Mb} / \mathrm{s}]}\end{array}\right.$ & 3,78 & 2,59 \\
\hline 1 & 10 & 4,47 & 3,26 \\
\hline 2 & 100 &
\end{tabular}

Ostatnie badanie polegało na sprawdzeniu zależności zmian wartości przepływności danych, nieprzypisanych do żadnej polityki jakościowej QoS (Quality of Service), od natężenia szyfrowanego IPsec-iem strumienia danych priorytetowych. Dane nieszyfrowane były generowane ze stałym natężeniem na poziomie $40 \%$ wartości przepustowości jednego łącza. Ruch przygotowany do szyfrowania narastał, aż do uzyskania $100 \%$ wartości przepustowości łącza. Jak widać na poniższym wykresie (Rys. 4), po uzyskaniu wartości przepływności powyżej 57\% nastąpiło zmniejszenie przepływności ruchu jawnego.

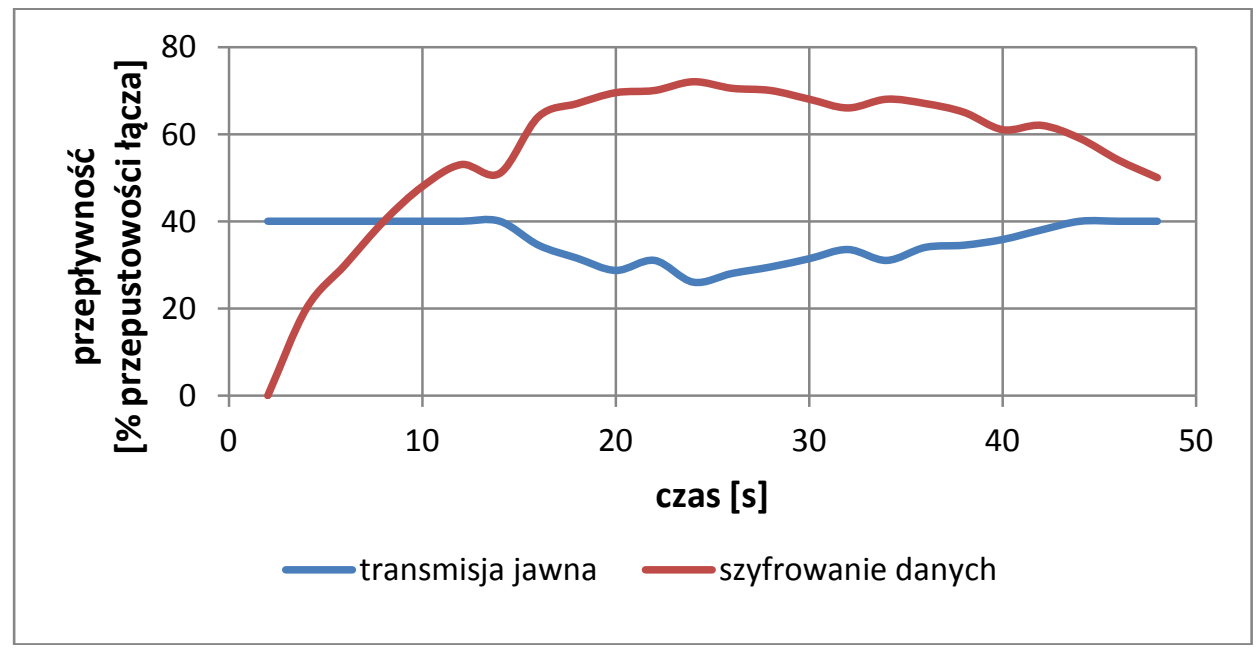

Rys. 4 Przeplywność strumieni w sieci

bez mechanizmów zwiększających niezawodność. 
Drugi wykres (Rys. 5.) pokazuje tą samą sytuację w sieci $\mathrm{z}$ zastosowaniem inżynierii ruchu TE (Traffic Engineering). Zastosowanie TE pozwoliło na „szybkie” przełączenie ruchu jawnego na inną ścieżkę w sieci o mniejszej zajętości łącza.

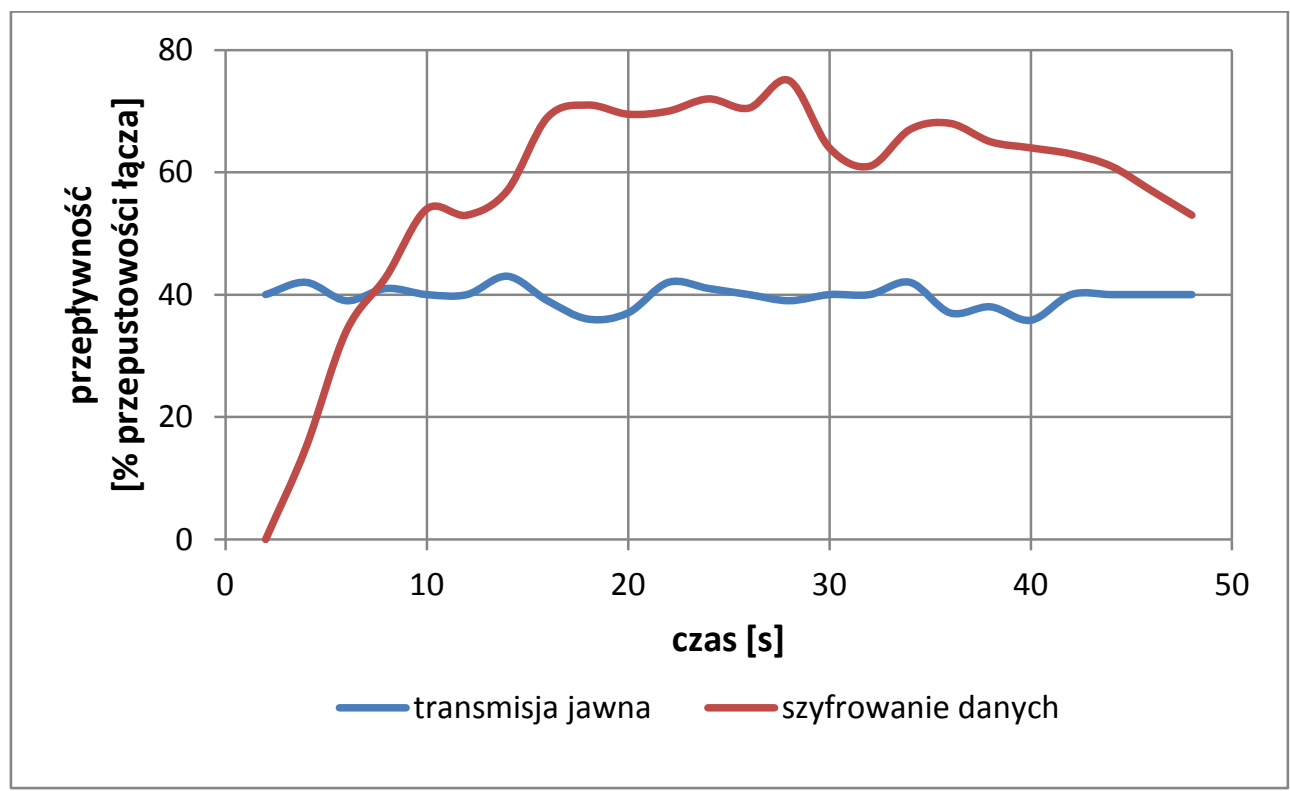

Rys. 5. Przeptywność strumieni w sieci z TE

\section{Podsumowanie}

Sieć szkieletowa $\mathrm{z}$ zaimplementowaną usługą MPLS VPN wzbogacona przy pomocy zestawu protokołu IPsec pozwala na poufne przesyłanie odseparowanych od siebie danych. Technika ta umożliwia dotrzymanie poufności danych jawnych i wrażliwych zarówno w sieciowych zasobach lokalnych jak i rozległych. Nie wpływa ona również degradująco na niezawodność.

Technika MPLS udostępnia wiele skalowalnych i elastycznych mechanizmów np.: zastosowanie algorytmu MD5 do podpisu wiadomości LDP sprawia, że tylko routery $\mathrm{z}$ wprowadzonym wcześniej id i hastem nawiązują i utrzymują sesje. Skonfigurowane hasło nie jest transmitowane w żadnym momencie sesji, co oznacza, że potencjalny nieautoryzowany router (destruktor) nie ma możliwości pozyskiwania transportowanych pakietów.

Jednakże czasami może zaistnieć potrzeba zwiększenia poziomu bezpieczeństwa np. dla danych wrażliwych - wówczas to istniej możliwość wprowadzenia dodatkowych elementów tj. protokoły z grupy FHRP (First Hop Redundancy Protocol), do których należą HSRP i VRRP. Implementacja jednego $\mathrm{z}$ nich pozwala na redundancję 
Analysis of MPLS VPN resistance to external threats

Analiza odporności MPLS VPN na narażenia zewnętrzne

węzła/ów (routera/ów) sieci szkieletowej, co pozwala na szybkie zastępowanie niezdatnych elementów przez zdatne routery oczekujące w trybie standby.

Wydajność tego rodzaju rozwiązań zależy od obciążenia sieci oraz od użytego rozwiązania. Protokół HSRP uzyskał dłuższe czasu reakcji od VRRP, co zapewne było spowodowane dłuższymi interwałami czasowymi pomiędzy przesyłanymi wiadomościami o stanie routerów.

Mimo to, uzyskany czas reakcji jest nieporównywalny z czasem potrzebnym specjaliście na dojechanie do uszkodzonego węzła i naprawie go bądź wymianie na sprawny. Dzięki temu usługa już po kilku sekundach jest w stanie dalej działać.

Uwzględniając powyższe zasadnym wydaje się stwierdzenie, że przedstawiane teoretyczne własności techniki MPLS VPN zostały potwierdzone $\mathrm{w}$ badaniach miejscowych. Otrzymane wyniki umożliwiają sprecyzowanie rekomendacji dla kolejny obszarów badawczych analizowanej techniki dotyczących:

- bezpieczeństwa (poufności, integralności), niezawodności (gotowości technicznej i funkcjonalnej) i jakości (dźwięku i obrazu),

- w środowisku heterogenicznym tj. różnorodność interfejsów, protokołów wewnątrz- i międzydomenowych oraz stacjonarności i mobilności użytkowników.

Wybrane rekomendacje zostały już fragmentarycznie poddane procesowi wybiórczej analizy i w dedykowanych warunkach środowiskowych przebadane, a wyniki zaprezentowano w publikacjach $[13 \div 16]$.

\section{Literatura}

[1] De Ghein L., MPLS Fundamentals, Cisco Press, Indianapolis 2007, ISBN: 1-58705-197-4.

[2] Serafin M., Sieci VPN Zdalna praca i bezpieczeństwo danych, Helion, Gliwice 2008, ISBN: 978-83-246-1521-6.

[3] Laskowski D., Lubkowski, P.: Confidential transportation of data on the technical state of facilities, Advances in Intelligent Systems and Computing 286, pp. 313-324, 2014.

[4] Bajda, A., Laskowski, D., Wrazen M.: Diagnostics the quality of data transfer in the management of crisis situation, Przeglad Elektrotechniczny 87 (9 A), pp. 72-78, 2011.

[5] Lubkowski P., Laskowski D.: The end-to-end rate adaptation application for real-time video monitoring, Advances in Intelligent Systems and Computing 224, pp. 295-305, 2013.

[6] Lubkowski P., Laskowski D., Pawlak E. Provision of the reliable video surveillance services in heterogeneous networks, Safety and Reliability: 
Methodology and Applications - Proceedings of the European Safety and Reliability Conference, ESREL 2014 pp. 883-888, 2015.

[7] Laskowski D., Lubkowski P., Pawlak E., Stańczyk P.: Anthropo-technical systems reliability, Safety and Reliability: Methodology and Applications Proceedings of the European Safety and Reliability Conference, ESREL 2014, pp. 399-407, 2015.

[8] Lubkowski P., Laskowski D.: Test of the multimedia services implementation in information and communication networks, Advances in Intelligent Systems and Computing 286, pp. 325-332, 2014.

[9] Kowalski M., Magott J., Nowakowski T., Werbińska-Wojciechowska S.: Exact and approximation methods for dependability assessment of tram systems with time window, European Journal of Operational Research 235(3), pp. 671-686, 2014.

[10] Nowakowski T., Werbińska-Wojciechowska S.: Expert system for means of transport maintenance processes performance: a comparative analysis for various types of rail vehicles. In: Safety and reliability: methodology and applications: proceedings of the European Safety and Reliability Conference, ESREL 2014, Wrocław, Poland, 14-18 September 2014, eds. Tomasz Nowakowski et al. Leiden: CRC Press/Balkema, pp. 1217-1225, 2015.

[11] Siergiejczyk M., Krzykowska K., Rosiński A.: Reliability assessment of cooperation and replacement of surveillance systems in air traffic. In „Proceedings of the Ninth International Conference Dependability and Complex Systems DepCoS-RELCOMEX”, editors: Wojciech Zamojski, Jacek Mazurkiewicz, Jarosław Sugier, Tomasz Walkowiak, Janusz Kacprzyk, given as the monographic publishing series - „Advances in intelligent systems and computing", Vol. 286. pp. 403-411. The publisher: Springer, 2014.

[12] Siergiejczyk M., Rosiński A., Krzykowska K.: Reliability assessment of supporting satellite system EGNOS. The monograph „New results in dependability and computer systems", editors: Wojciech Zamojski, Jacek Mazurkiewicz, Jarosław Sugier, Tomasz Walkowiak, Janusz Kacprzyk, given as the monographic publishing series - „Advances in intelligent and soft computing", Vol. 224. pp. 353-364. The publisher: Springer, 2013.

[13] Lubkowski P., Laskowski D.: The selected issues of reliable identification of object in transport systems using video monitoring services, Communication in Computer and Information Science 0471, pp. 59-68, 2014.

[14] Laskowski D., Lubkowski P., Kwasniewski M.: Identification of suitability services for wireless networks, Przeglad Elektrotechniczny 89 (9), pp. 128-132, 2013. 
Analysis of MPLS VPN resistance to external threats

Analiza odporności MPLS VPN na narażenia zewnętrzne

[15] Bylak M., Laskowski D.: Assessment of network coding mechanism for the network protocol stack 802.15.4/6LoWPAN, Advances in Intelligent Systems and Computing 224, pp. 75-82, 2013.

[16] Bylak M., Laskowski D.: Diagnosis coding efficiency of network coding mechanism for wireless networks, Przeglad Elektrotechniczny 89 (9), pp. 133-138, 2013.

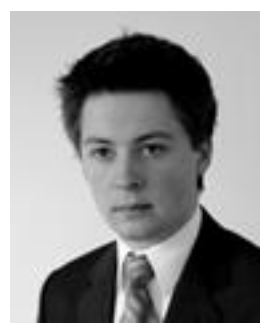

Mgr inż. Marcin Pólkowski jest specjalista ds. Sieci Teleinformatycznych $w$ Transbit Sp. z o.o., w 2014r. ukończyt Wydziat Elektroniki Wojskowej Akademii Technicznej. Zajmuje sie analiza zjawisk zachodzacych podczas transferu danych $w$ złożonych strukturach wykorzystujacych nowoczesne i perspektywiczne techniki $i$ technologie $w$ sieciach telekomunikacyjnych $i$ teleinformatycznych. Zasadnicze obszary zainteresowania to bezpieczeństwo, niezawodność i jakość obiektów technicznych $w$ aspekcie ich praktycznego zastosowania $w$ sieciach heterogenicznych.

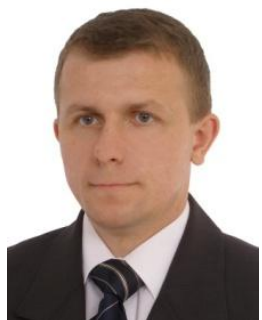

Dr hab. inż. Dariusz Laskowski ukończyt Wydziat Elektroniki Wojskowej Akademii Technicznej, gdzie obecnie pracuje. Zajmuje sie wieloaspektowa analiza zjawisk determinujacych poprawność realizacji ustug $w$ heterogenicznych systemach $i$ sieciach oferujacych przesyt danych. Gtówne obszary zainteresowania to niezawodność, bezpieczeństwo, jakość $i$ przeżywalność obiektów technicznych $w$ aspekcie ich praktycznego zastosowania $w$ sieciach heterogenicznych. 